\title{
Microstructure and Mechanical Behavior in Dissimilar SAF 2205/API X52 Welded Pipes
}

\author{
Brahim Belkessa $^{1,2} \cdot$ Djamel Miroud $^{2} \cdot$ Naima Ouali $^{1} \cdot$ Billel Cheniti $^{1}$
}

Received: 29 January 2016/Revised: 4 April 2016/Published online: 4 May 2016

(c) The Chinese Society for Metals and Springer-Verlag Berlin Heidelberg 2016

\begin{abstract}
The welding of a duplex stainless steel SAF 2205 DSS (UNS 31803) and high strength low alloy steel API X52 by shielded metal arc welding process was conducted using two different filler metals, the duplex E2209 and austenitic E309 grade. The microstructures of the dissimilar metal joints have been investigated by optical microscopy, scanning electron microscopy, energy-dispersive spectroscopy (EDS) and X-ray diffraction. EDS analysis at the interface X52 weld metal showed an evident gradient variation of $\mathrm{Cr}$ and $\mathrm{Ni}$ between boundaries of fusion and type II, where the highest hardness value was recorded. Tensile strength and toughness values of the weld metal produced by E309 electrode are slightly higher than those of the weld metal produced by E2209 electrode. Potentiodynamic polarization tests of different regions of the welded joints evaluated in $3.5 \% \mathrm{NaCl}$ solution exhibit a high corrosion resistance of both weld metals.
\end{abstract}

\section{KEY WORDS: Dissimilar metals welding; 2205 duplex stainless steel; API X52 HSLA steel; Heat-affected} zone; Mechanical properties

\section{Introduction}

Dissimilar metal welding (DMW), as a joining technique, is most often used where a transition in mechanical properties and/or performance in service are required [1]. Currently, dissimilar material joining is inevitable in engineering industries; it is particularly applied for joining stainless steel and carbon or low alloy steels, which are widely used in pressure vessels, boilers, heat exchangers of power generation industry and petrochemical plants $[2,3]$.

Available online at http://link.springer.com/journal/40195

Brahim Belkessa

b.belkessa@csc.dz

1 Research Center in Industrial Technologies, CRTI, P.O. Box 64, 16014 Cheraga, Algiers, Algeria

2 Laboratory of Sciences and Materials Engineering, LSGM, FGMGP, University of Sciences and Technology Houari Boumediene, BP 32 El Alia, Bab Ezzouar, 16111 Algiers, Algeria
The joining of dissimilar materials is generally more challenging than that of similar materials, due to various factors such as the differences in chemical compositions, physical and mechanical properties of the welded base metals. These differences cause a serious complication in selection of filler metals, which is compatible to both base metals $[4,5]$.

Indeed, during dissimilar welding, some problems and difficulties, such as the formation of brittle intermetallic phases, caused by the carbon migration resulting in loss in strength of ferritic material adjacent to the weld interface and an increase in hardness of the weld metal (carbonenriched zone) [6,7], and also, the difference in thermal expansion coefficients, resulting in difference in thermal residual stresses across the different regions of weldments, and the difficulties in carrying out the post-weld heat treatment, especially the harmful precipitation at elevated temperatures [8]. Another problem encountered in dissimilar welding is the formation of high and low melting point phases, where generally requires to use a suitable filler metal to control the segregation phenomenon. 
The main purpose in DMW is to select the filler metal, which allows to obtain stable austenite with a small amount of ferrite in the first weld pass, so the weld solidification cracking is avoided in the austenitic weld metal $[1,9]$.

Because of their excellent combination of the mechanical properties and corrosion resistance, duplex ferritic/ austenitic stainless steels are widely used in a variety of applications such as oil and gas industries, chemical and power plants [10-12].

Duplex stainless steels have higher strength than austenitic stainless steels, higher toughness than ferritic stainless steels, good weldability and high resistance to stress corrosion crack.

These good properties depend on the two phases of the microstructures, which consist of approximately equal amounts of austenitic $\gamma$ and $\delta$ ferrite $[13,14]$.

An important problem in welding of DSS is the change in the austenite/ferrite balance that affects the material ductility. When the ferrite content is higher than the austenite, it will lead to the precipitation of intermetallic phases, such as $\sigma$ phase, which affects the toughness and corrosion resistance in the duplex stainless steels [15]. Therefore, to reduce these effects, it is important to make a careful selection of welding materials and parameters.

In order to understand the structure-property relationship between the ferritic and duplex stainless steels (DSS), we attempt to produce dissimilar joints between duplex stainless steel and low alloy steel, by shielded metal arc welding process (SMAW), using two different welding consumables. The microstructure, mechanical properties and corrosion behavior of the weldments were characterized in this work.

\section{Experimental Material and Procedure}

The base metals employed in this work were duplex stainless steel, 2205 DSS (UNS 31803) and high strength low alloy steel API X52. The materials were received in a tube form of $152.4 \mathrm{~mm}$ diameter and $12 \mathrm{~mm}$ in wall thickness. A multipass shielded metal arc welding process (SMAW) was employed to join this combination, by using two different filler metals: a duplex stainless steel electrode (E2209) and an austenitic electrode (E309). The chemical composition of base and weld metals is reported in Table 1 .

A single $\mathrm{V}$ groove with an angle of $60^{\circ}$ was prepared. The schematic of welded joint is shown in Fig. 1a, and macrosection of the joint is shown in Fig. 1b. The welding parameters are summarized in Table 2.

After welding, mechanical tests and metallurgical investigation were carried out. Metallographic sections transverse to the welding direction were prepared for optical metallography. The X52 steel was etched with Nital (100 mL of ethyl alcohol and $2 \mathrm{~mL}$ of nitric acid). The DSS was etched with a Beraha reagent $\left(0.7 \mathrm{~g} \mathrm{~K}_{2} \mathrm{~S}_{2} \mathrm{O}_{5}\right.$, $20 \mathrm{~mL} \mathrm{HCL}$, and $80 \mathrm{~mL} \mathrm{H}_{2} \mathrm{O}$ ).
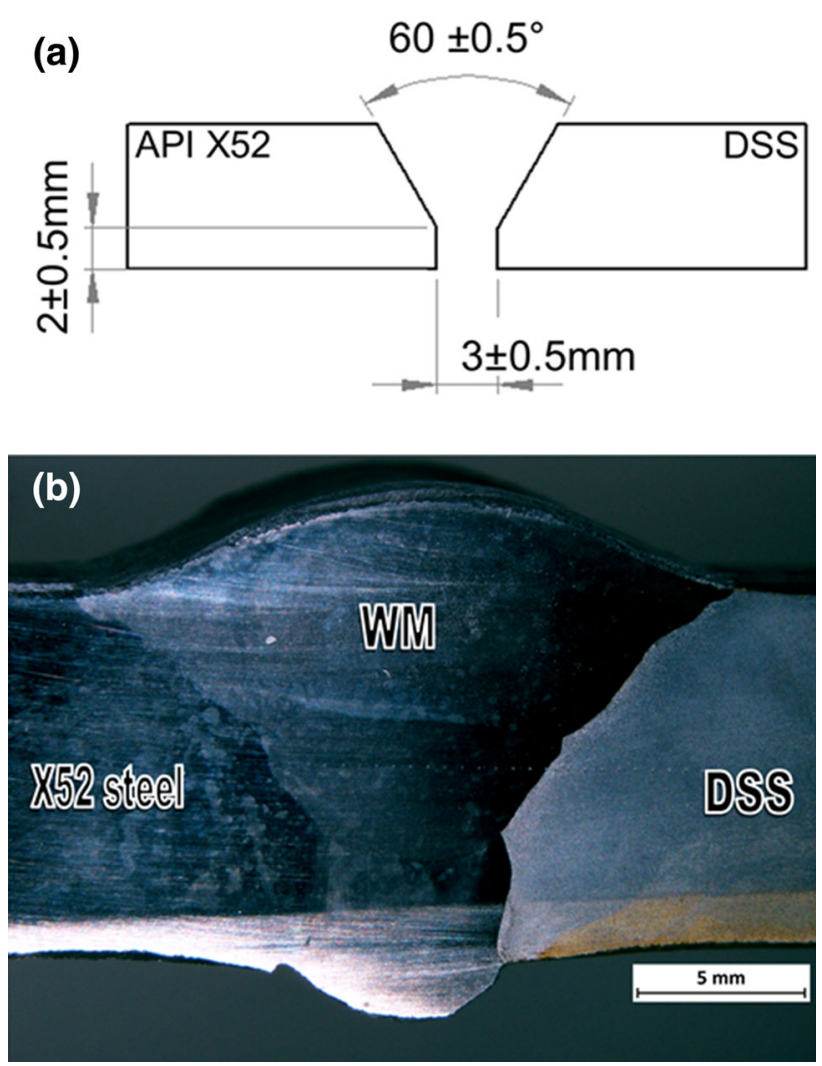

Fig. 1 a Single V groove welded joint, b macrosection of dissimilar welded joint

Table 1 Chemical composition of the base and weld metals (wt $\%$ )

\begin{tabular}{lllllllllll}
\hline Element & $\mathrm{C}$ & $\mathrm{Mn}$ & $\mathrm{Si}$ & $\mathrm{P}$ & $\mathrm{S}$ & $\mathrm{Cr}$ & $\mathrm{Ni}$ & $\mathrm{Mo}$ & $\mathrm{N}$ & $\mathrm{Fe}$ \\
\hline $\begin{array}{l}\text { Base metals } \\
\quad\end{array}$ & & & & & & & & & & \\
UNS 31830 & 0.029 & 1.7 & 0.46 & 0.02 & 0.012 & 21.58 & 5.27 & 2.96 & 0.2 & Balance \\
API X-52 & 0.14 & 1.2 & 0.24 & 0.017 & 0.005 & 0.058 & 0.041 & 0.014 & - & Balance \\
Weld metals & & & & & & & & & \\
E2209 & 0.03 & 1.0 & 0.90 & 0.026 & 0.02 & 21.8 & 6.8 & 3.1 & 0.15 & Balance \\
E309 & 0.04 & 1.4 & 0.56 & 0.03 & 0.02 & 19.9 & 9.8 & 0.8 & - & Balance \\
\hline
\end{tabular}


Table 2 Welding parameters

\begin{tabular}{lllllll}
\hline $\begin{array}{l}\text { Welding } \\
\text { process }\end{array}$ & $\begin{array}{l}\text { Filler } \\
\text { metals }\end{array}$ & $\begin{array}{l}\text { Welding } \\
\text { voltage }(\mathrm{V})\end{array}$ & $\begin{array}{l}\text { Welding } \\
\text { current }(\mathrm{A})\end{array}$ & $\begin{array}{l}\text { Electrode } \\
\text { diameter }(\mathrm{mm})\end{array}$ & $\begin{array}{l}\text { Welding speed } \\
(\mathrm{mm} / \mathrm{min})\end{array}$ & $\begin{array}{l}\text { Flow rate } \\
(1 / \mathrm{min})\end{array}$ \\
\hline SMAW & E2209 & $22-28$ & $80-110$ & 2.5 & $70-90$ & $10-12$ \\
& E309 & & & & \\
\hline
\end{tabular}

Microstructural examination of the samples was done using a ZEISS optical microscope and a scanning electron microscope (JEOL JSM 6360). The ferrite and austenite volume fractions were estimated by automatic image analysis using a computer program attached to the optical microscope. Energy-dispersive X-ray spectrometry (EDS) was employed to determine the chemical composition in the different zones of weldments.

$\mathrm{X}$-ray diffraction (XRD) was carried out on different specimens using an X'PERT PRO X-ray diffractometer with the parameters of angular interval $20: 20^{\circ}-100^{\circ}$, angular step: $0.026^{\circ}$ and time per step: $72 \mathrm{~s}$.

In order to examine the mechanical behavior of the dissimilar metals welded joints, hardness, impact and tensile tests were performed. Standard tensile specimens, according to the ASME IX, were machined, and the tests were done on an SATEC INSTRON tensile test machine. The hardness measurements were taken on a Buehler Micromet Microhardness and Instron Wolpert hardness testers under $200 \mathrm{~g} / \mathrm{f}$ and $10 \mathrm{~kg} / \mathrm{f}$, respectively.

Charpy V impact specimens were machined with the normalized dimensions of $55 \mathrm{~mm} \times 10 \mathrm{~mm} \times 10 \mathrm{~mm}$. Impact tests were performed at room temperature using an INSTRON Pendulum impact tester.

The corrosion behavior of the dissimilar metals weld was evaluated by potentiodynamic polarization investigations. To confirm the accuracy of electrochemical measurements, the experiments were repeated at least three times, in $3.5 \%$ sodium chloride $(\mathrm{NaCl})$ solution at room temperature using a Voltalab instrument.

\section{Results and Discussion}

\subsection{Microstructure}

The microstructures of DSS and X52 steel base metals are shown in Figs. 2a and 3a, respectively. The DSS base metal (DSS BM) has shown an elongated grain structure along rolling direction, where austenite $(\gamma)$ phase distributes in the ferrite $(\delta)$ matrix with average amounts of $54.1 \%$ of ferrite and $45.9 \%$ of austenite, while the microstructure of X52 base metal (X52 BM) consists of a rolled microstructure, mainly formed by a ferritic matrix (white area) and pearlitic colonies (black area). Both
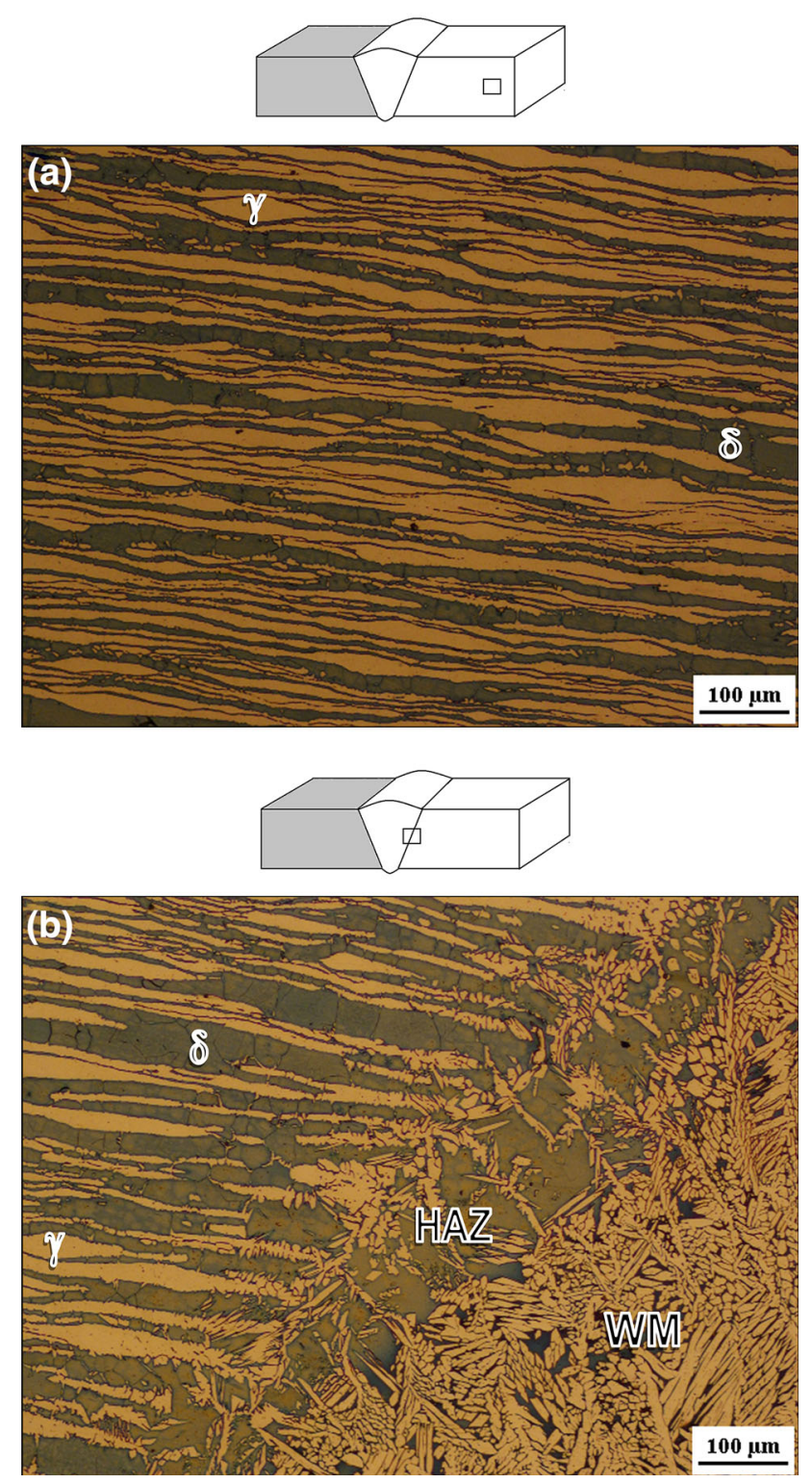

Fig. 2 Optical micrograph of DSS: a base metal, b HAZ

phases showed the rolling direction, which is related to the thermomechanical rolling process.

During welding, heat-affected zones (HAZs) are generated on either side of the weld metal adjacent to the fusion boundaries. These zones undergo metallurgical transformations due to the welding thermal cycle that could be critical for welded joint properties. 

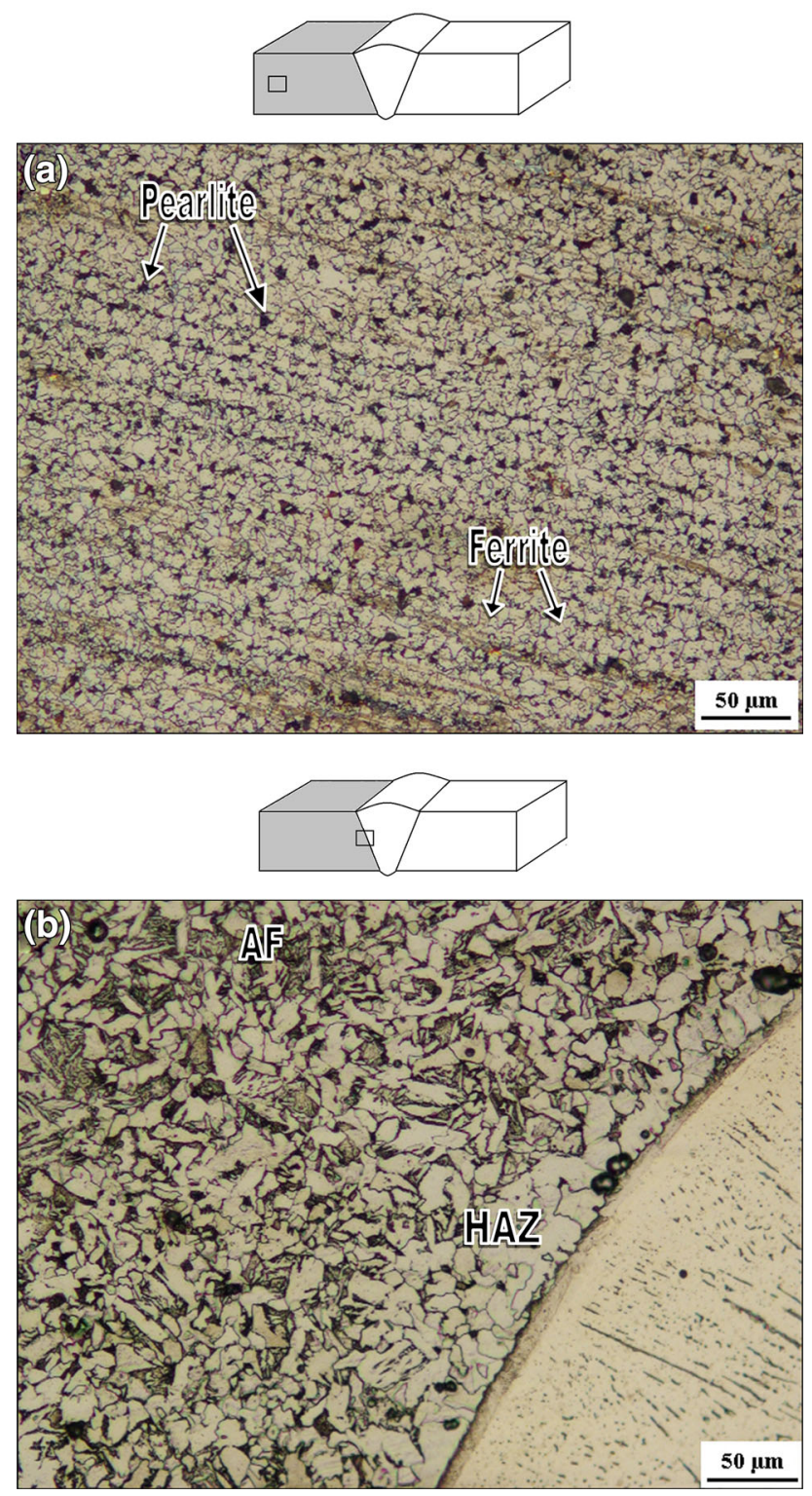

Fig. 3 Optical micrograph of X52 steel: a base metal, b HAZ

Figure $2 b$ shows the optical micrograph of the HAZ in the duplex side (DSS HAZ), which is characterized by a high content of ferrite (about $60.8 \%$ ), compared to base metal, and consequently a low amount of austenite is present in the region. This is due to the high peak of temperature induced during welding, where the structure is transformed to ferrite during thermal cycle of welding, and the austenite grains reformed by cooling to room temperature $[13,16]$.

The heat-affected zone of X52 steel (X52 HAZ) illustrated in Fig. 3b, shows a recrystallized microstructure, which is composed of the coarse-grained ferrite, the acicular ferrite (AF) and small amount of the pearlite.

The optical micrographs of E309 WM and E2209 WM are shown in Fig. 4a and b. Both of weld metal structures
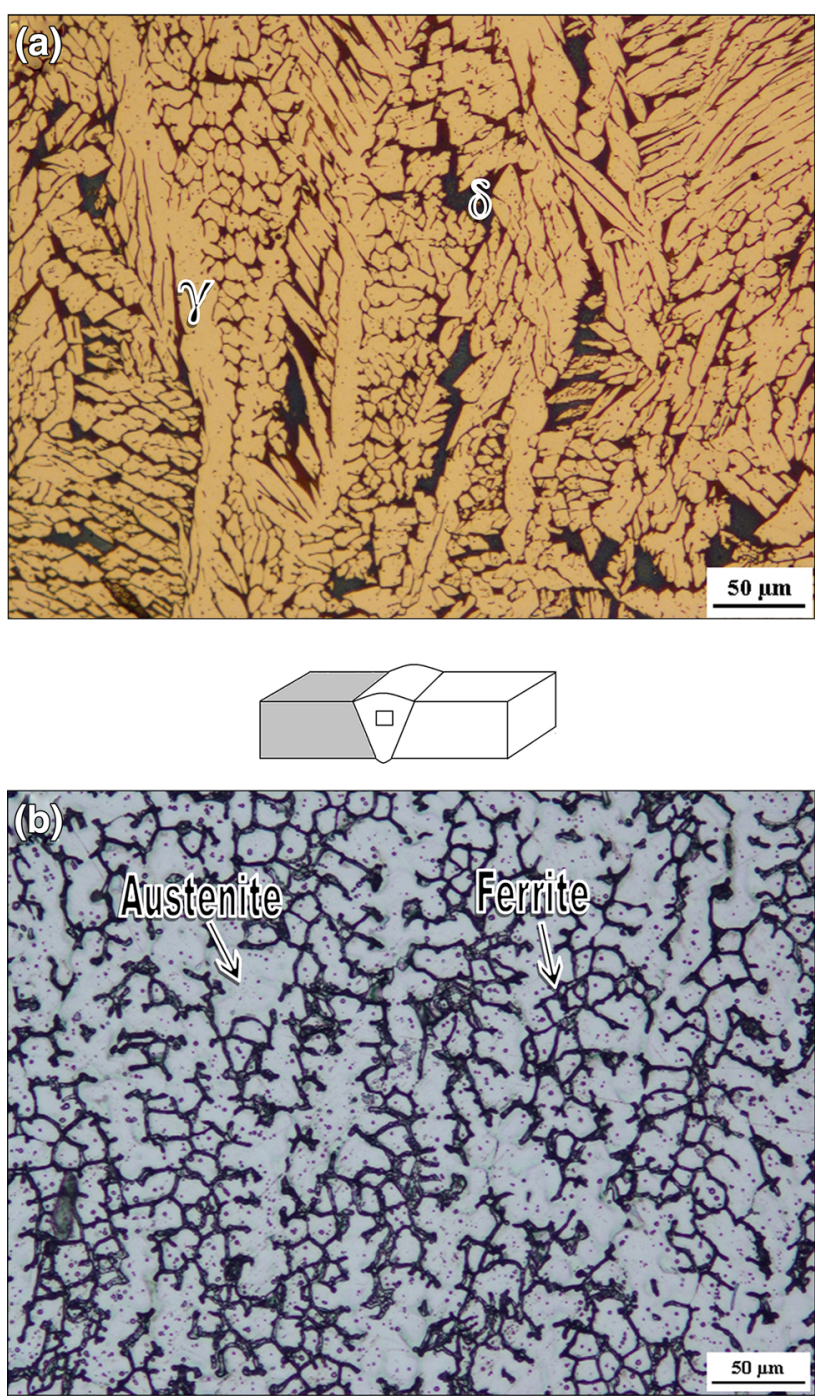

Fig. 4 Optical micrograph of weld metals: a E2209 WM, b E309 WM

are composed of the ferrite and the austenite. However, the morphologies of these phases are different: A structure of Widmanstätten austenite grains within the matrix of ferrite is observed in the weld metal produced by E2209 electrode, while the interdendritic ferrite in the austenite matrix structure is found in the weld metal produced by E309 electrode.

Microstructural features of X52 steel and weld metal interface are shown in Fig. 5. As illustrated in this figure, a type II boundary (characteristic of dissimilar metal joint) is observed adjacent to the fusion boundary in both weld metals at the X52 steel side. This boundary forms in the solid state during weld cooling, allowing the austenite grain growth across the fusion boundary [1]. Metallographic 


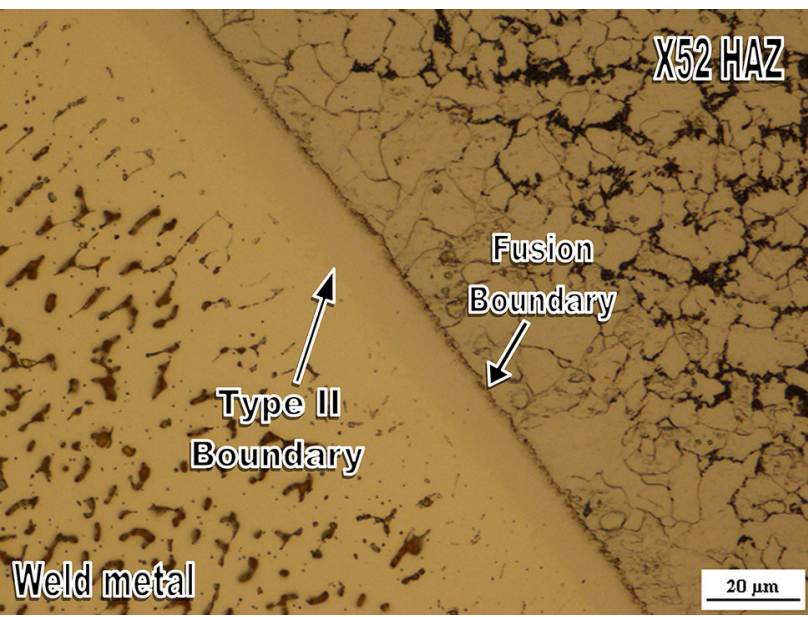

Fig. 5 Microstructure of X52 steel/E309 weld metal interface

examination reveals the presence of a narrow zone of about $50 \mu \mathrm{m}$ between the fusion boundary and the type II boundary. The development of such a boundary was attributed to the difference in crystal structure between the materials being assembled $[8,11]$.

The results of XRD analysis performed on the DSS base metal and the two weld metals are shown in Fig. 6. Only $\delta$ and $\gamma$ phases were identified in both weld metals. No precipitates or harmful intermetallic phases as $\sigma$ phase or carbides were detected.

The EDS line scanning at the X52 steel/weld metal interface reveals a variation of alloying elements across this interface, as shown in Fig. 7. The content of chromium decreases significantly near the fusion line, more greatly than that of nickel.

Due to the thermal cycle induced by the welding process, a carbon migration is observed across the fusion boundary from X52 base metal into the weld metal, which is discussed deeply in the literature $[8,10]$. This result of
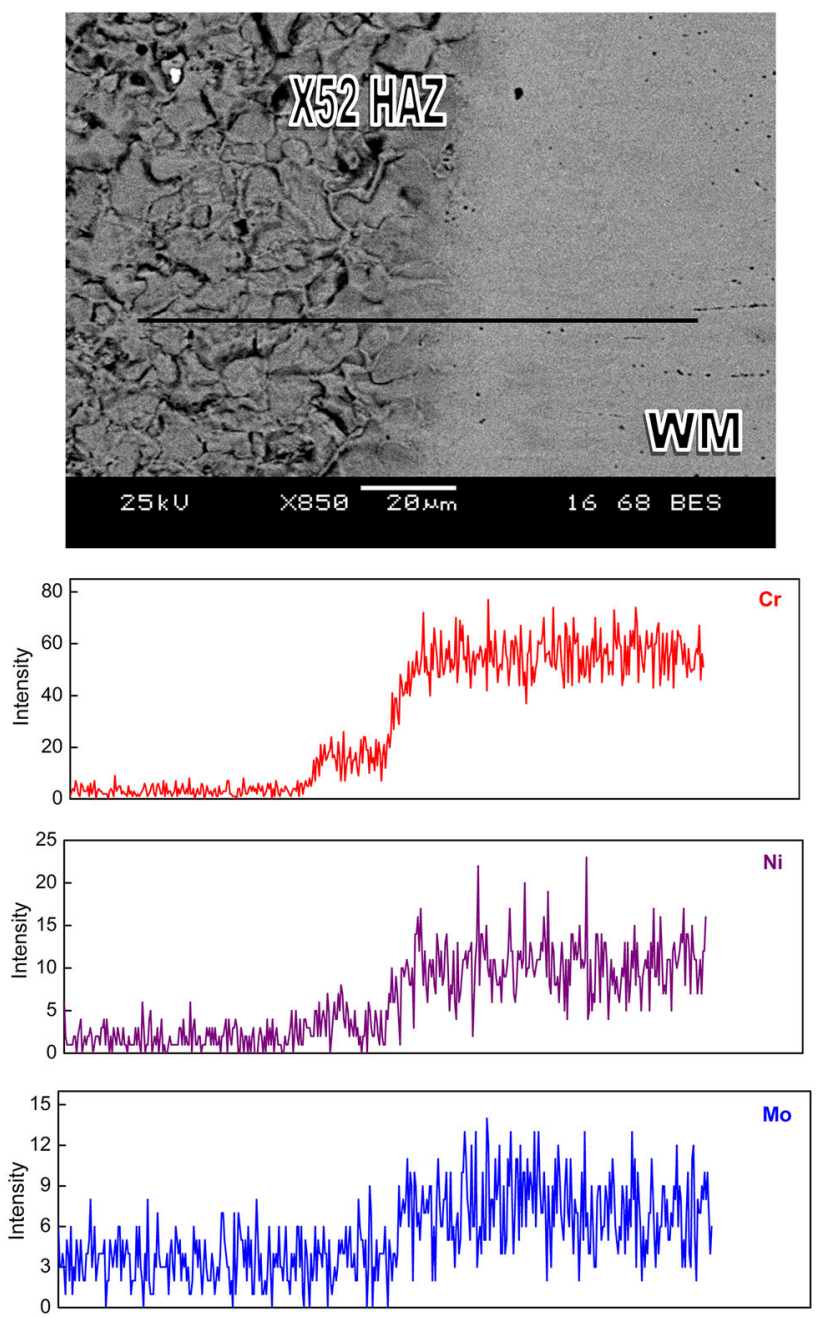

Fig. 7 EDS line scanning across the X52 steel/E309 weld metal interface

the carbon gradient is presented (high $\mathrm{C}$ in X52 BM), showing the affinity of carbon for the high chromium weld metal. Furthermore, the fast cooling rate of molten pool

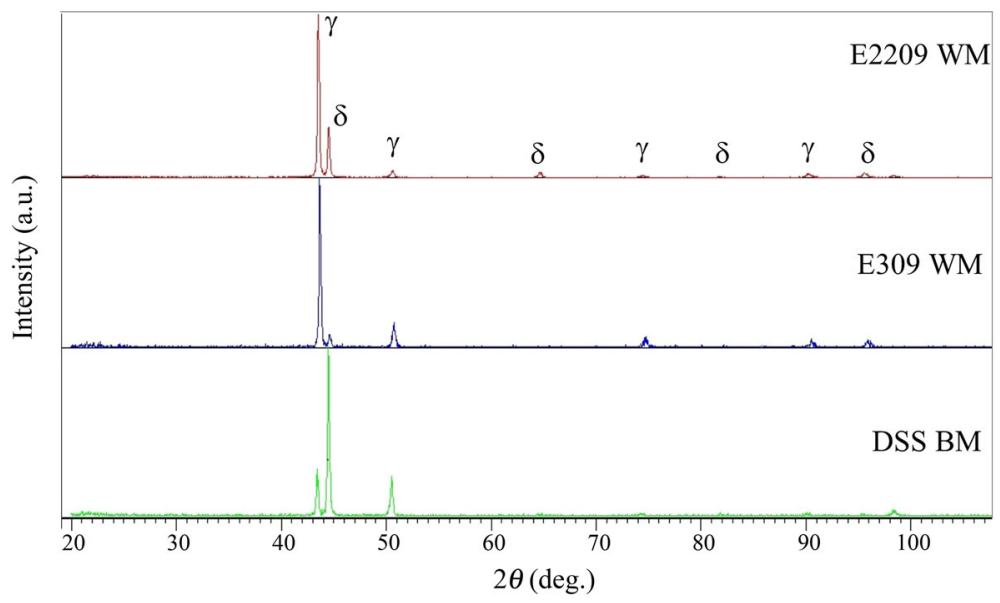

Fig. 6 X-rays diffractograms of DSS base metal and both weld metals 
Table 3 Tensile properties of the weld metals

\begin{tabular}{llll}
\hline Material & Tensile strength (MPa) & Elongation (\%) & Failure location \\
\hline 2205 DSS base metal & 768.15 & 35.81 & - \\
API X52 base metal & 673.27 & 19.36 & - \\
E2209 weld metal & 652.76 & 17.72 & X52 steel base metal \\
E309 weld metal & 669.59 & 18.64 & X52 steel base metal \\
\hline
\end{tabular}

and the dilution of X52 steel results in segregation of alloying elements near the fusion line [10]. The EDS line scanning results are almost the same for both weld metals.

\subsection{Mechanical Properties}

Two tensile tests of the samples with standard dimensions were performed on each welded joint. The tensile properties of the dissimilar weld metals are reported in Table 3. The rupture of all specimens occurred in the X52 steel side. Tensile strength values of the welded joints produced by E309 electrode are slightly higher than the ones obtained by E2209 electrode.

Figure 8 shows the hardness profiles of the dissimilar welded joints. The tendency of hardness evolution is almost the same for both weldments (E2209 and E309).

The hardness values of the weld metals are higher than that of the X52 BM and X52 HAZ, which is evident because of the differences in the chemical compositions.

The increase in hardness in DSS HAZ is due to the increase in the ferrite content in this zone, caused by the welding thermal cycles. Furthermore, the lowest hardness values are recorded in the X52 HAZ owing to the grain growth of the microstructure in this region.

Microhardness profiles of X52 steel/weld metals interface are shown in Fig. 9. The peaks of hardness observed

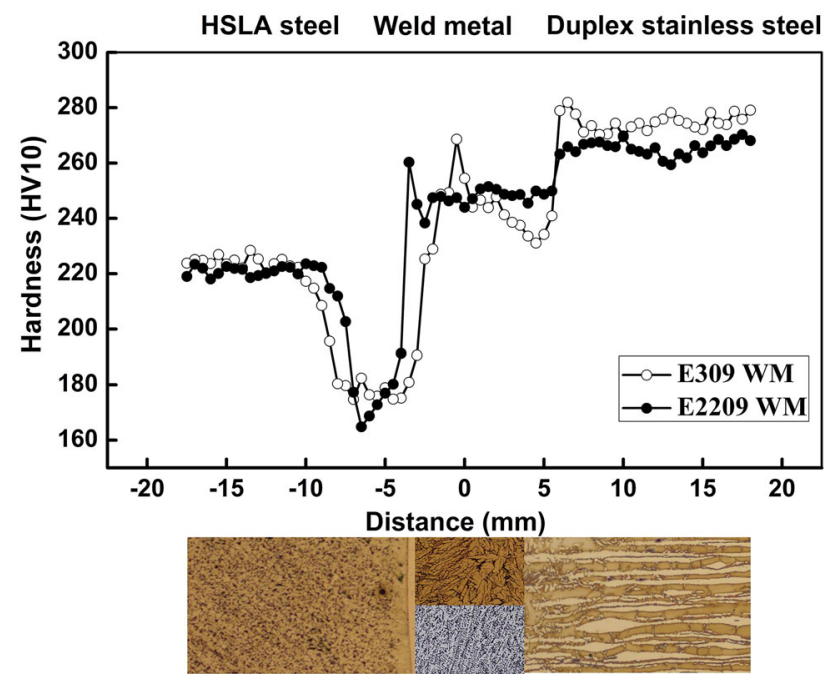

Fig. 8 Evolution of hardness in the dissimilar welded joints

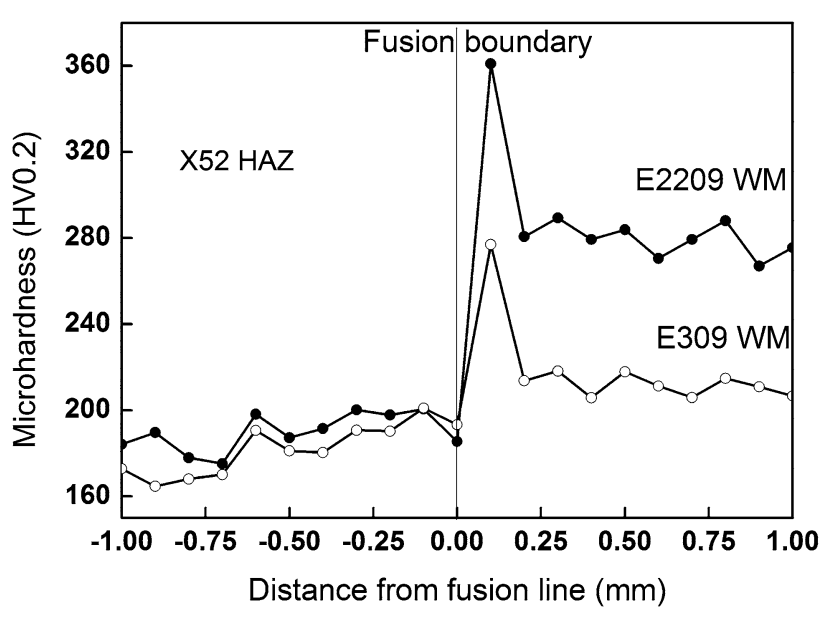

Fig. 9 Microhardness profiles at the X52 steel/weld metals interface

in the narrow zone between the boundary of fusion and type II boundary, at the interface between X52 steel and the fusion line, are attributed to the presence of harder microconstituents in this region, due to the migration of carbon from the HSLA steel to the weld metal.

The difference in hardness behavior in these two weld metals is attributed to the gradient in alloying elements, such as molybdenum, which is three times higher in E2209 WM than in E309 WM that promotes a ferritic microstructure, thus increasing hardness at high tempering temperatures.

The toughness values of DSS BM, DSS HAZ, X52 BM, X52 HAZ and both weld metals (E309 and E2209) are

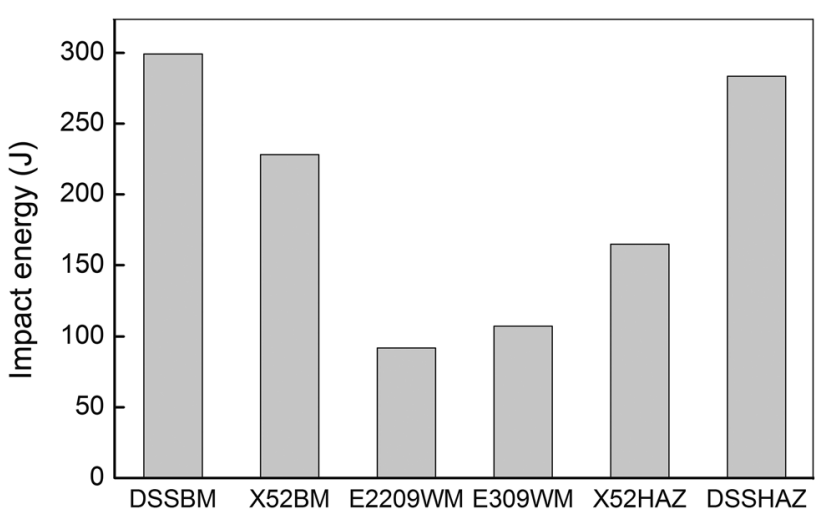

Fig. 10 Charpy impact test values of dissimilar weld metals 

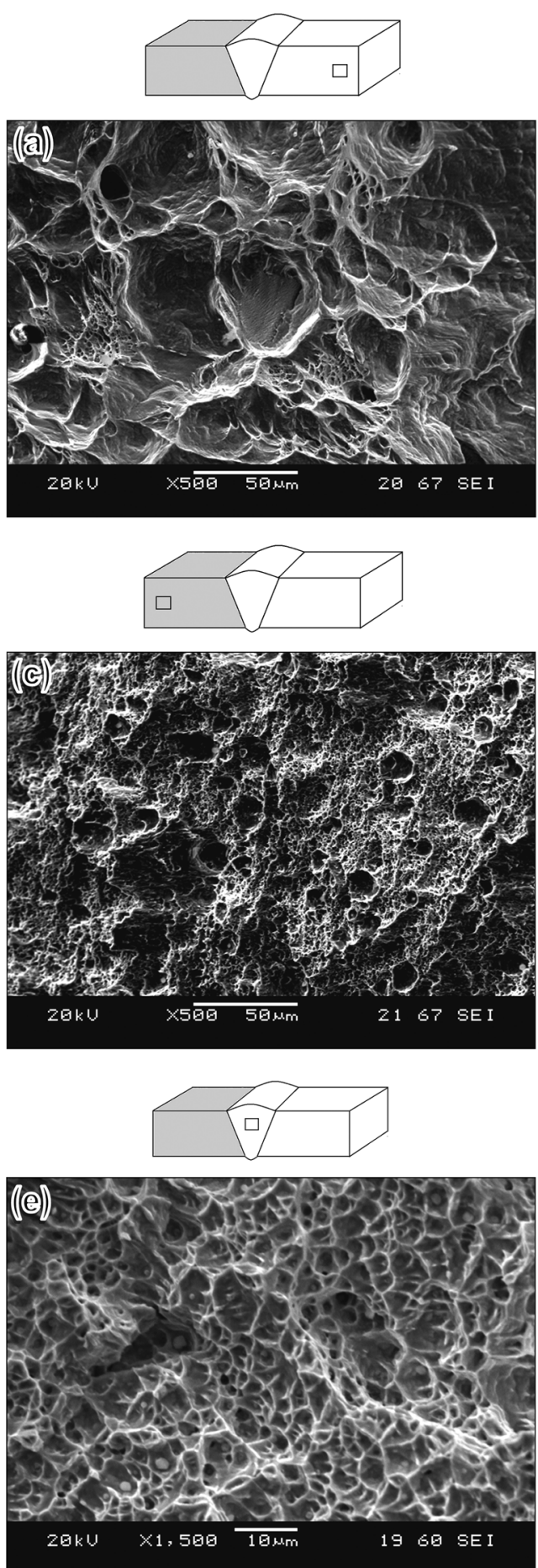
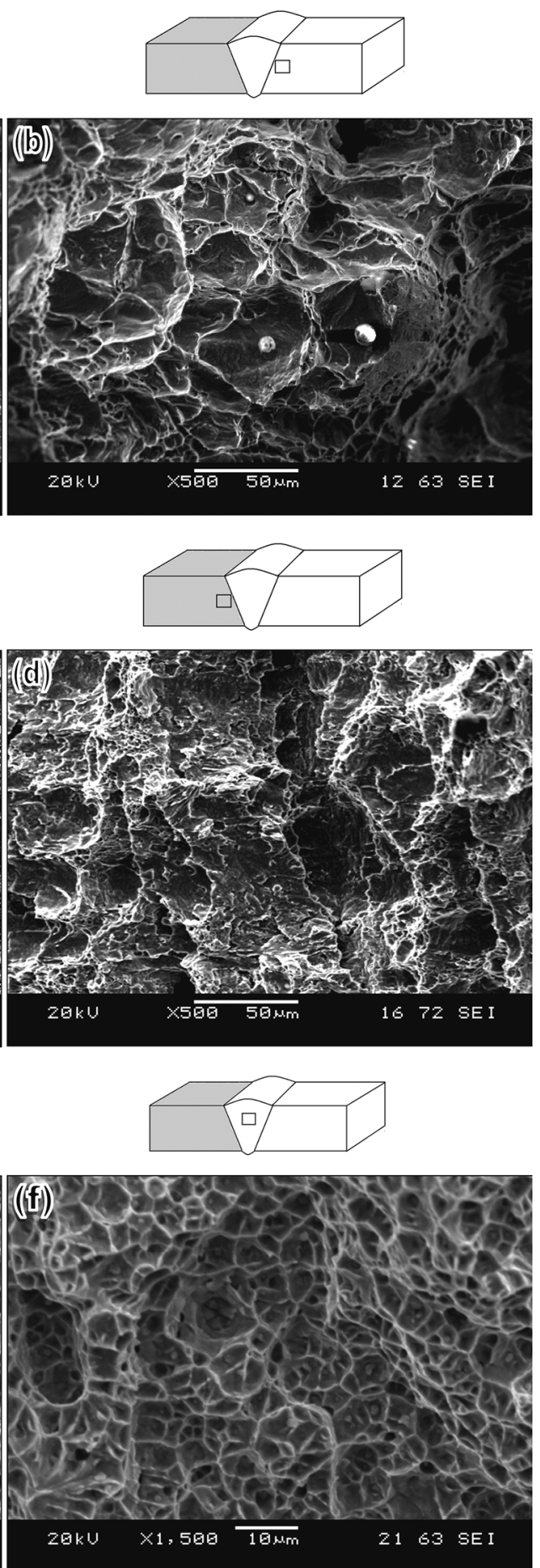

Fig. 11 SEM micrograph of the fractured impact test specimens: a DSS BM, b DSS HAZ, c X52 BM, d X52 HAZ, e E309 WM, f E2209 WM

resumed in Fig. 10. The data imply that the toughness of X52 HAZ is lower than that of the X52 BM ones, which may be attributed to the grain coarsening and the presence of hard constituents in this area. On the other hand, the toughness recorded in E2209 weld metal is slightly higher than that in the E309 weld metal. Furthermore, the ferrite- austenitic balance presented in the DSS BM exhibits the highest toughness value at room temperature.

The fracture surfaces of base metals, HAZs and weld metals observed by SEM are shown in Fig. 11. The fracture modes in DSS BM, DSS HAZ and X52 BM are all typical ductile dimple fracture (Fig. 11a-c). However, the X52 


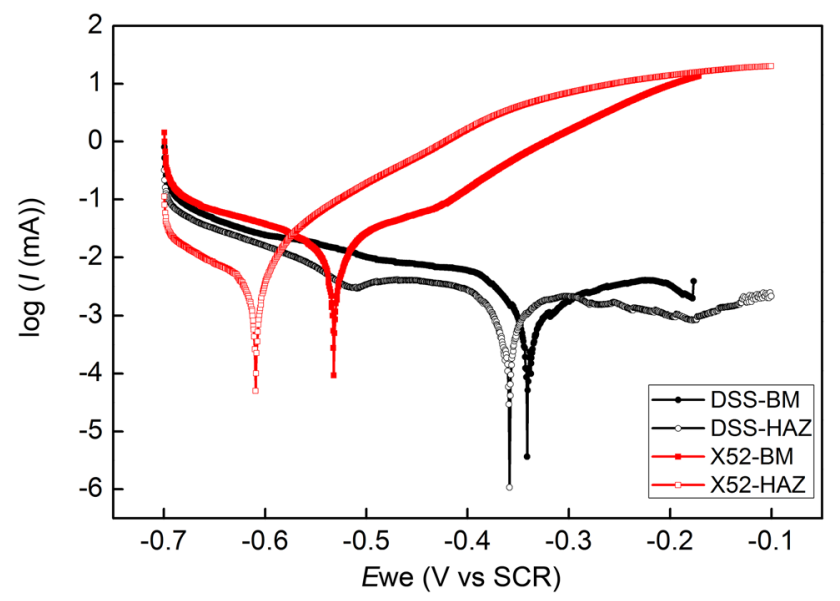

Fig. 12 Potentiodynamic polarization curves of DSS and X52 steel base metal and $\mathrm{HAZ}$ in $3.5 \% \mathrm{NaCl}$ solution at room temperature

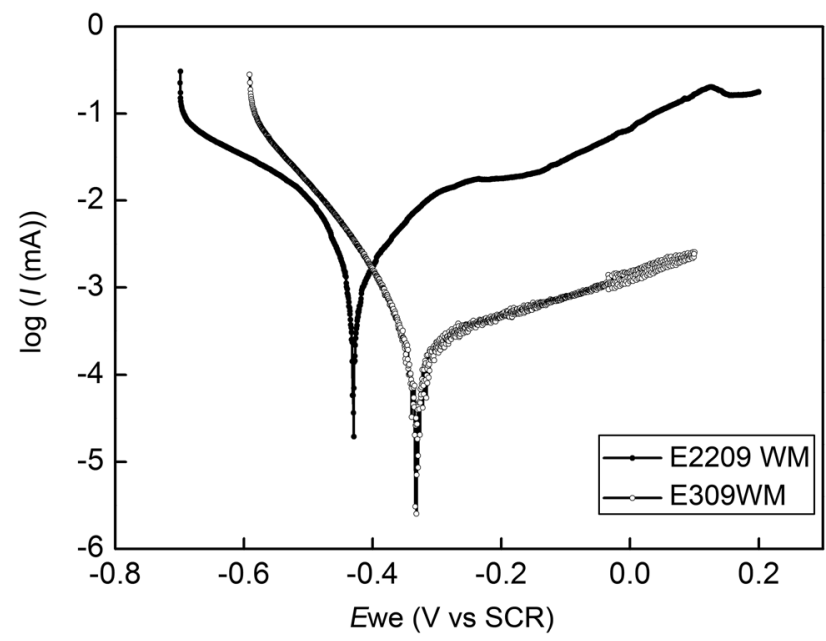

Fig. 13 Potentiodynamic polarization curves of weld metals in $3.5 \%$ $\mathrm{NaCl}$ solution at room temperature

HAZ fractography shows a mixed cleavage-ductile fracture (Fig. 11d). This can be assigned to the existence of two regions: a carbon-depleted zone in the X52 HAZ immediately adjacent to the fusion boundary, where soft ferrite forms in this region which resulted in a premature failure in creep, and a narrow brittle hard zone between the fusion boundary and the type II boundary (Fig. 6) [1].

The weld metal specimens reveal a ductile fracture mode, where a large number of dimples can be observed.
More fine dimples are distributed in E309 WM with 3-5 $\mu \mathrm{m}$ average size (Fig. 11e) compared to $6-8 \mu \mathrm{m}$ average size recorded in E2209 WM (Fig. 11f).

\subsection{Corrosion Behavior}

The potentiodynamic polarization curves of base metals, heat-affected zones and weld metals in $3.5 \% \mathrm{NaCl}$ solution at room temperature are illustrated in Figs. 12 and 13.

The corrosion current $\left(I_{\text {corr }}\right)$ and the corrosion potentials $\left(E_{\text {corr }}\right)$ of the different samples are summarized in Table 4. These data were obtained for at least three replicates according to Tafel extrapolation method.

As shown in Fig. 12, the potentiodynamic polarization curves of DSS BM and DSS HAZ are almost similar in the shape and consist of a wide passive region, showing a general property of duplex stainless steels [17].

The potential corrosion of X52 BM is higher than that of X52 HAZ. However, a low corrosion current is recorded in X52 HAZ (Fig. 12).

Figure 13 shows clearly that E309 WM exhibits higher corrosion resistance in $3.5 \mathrm{~mol} / \mathrm{L} \mathrm{NaCl}$ solution $\left(E_{\text {corr }}=-341.42 \mathrm{mV}\right.$ and $\left.I_{\text {corr }}=0.226 \mathrm{~mA}\right)$ than E2209 WM. This can be explained by high ferrite content in E2209 WM compared to E309 WM. Further, $\delta$ ferrite with high chromium content may have detrimental effect on the corrosion resistance due to the potential difference between the $\delta$ ferrite and $\gamma$ austenite phases [18].

\section{Conclusion}

(1) A type II boundary is formed in the weld metal at the X52 steel side, for both weldments performed with E2209 and E309 electrodes.

(2) A highest value of the hardness is recorded in the narrow zone between the fusion boundary and type II boundary, which is attributed to the presence of harder microconstituents in this region, due to the migration of carbon from HSLA steel to weld metal.

(3) The modes of the fracture surface for all specimens are ductile except for the X52 steel HAZ, which is quasi cleavage because the narrow hard and brittle band present in this zone.

Table 4 Electrochemical corrosion parameters obtained from potentiodynamic polarization curves of various specimens in $3.5 \% \mathrm{NaCl}$ solution at room temperature

\begin{tabular}{lcccrrr}
\hline Sample & DSS BM & DSS HAZ & X52 BM & X52 HAZ & E2209 WM & E309 WM \\
\hline$E_{\text {corr }}(\mathrm{mV})$ & -339.85 & -357.50 & -632.34 & -708.42 & -430.48 & -341.42 \\
$I_{\text {corr }}(\mu \mathrm{A})$ & 0.284 & 0.292 & 6.860 & 3.370 & 0.367 & 0.226 \\
\hline
\end{tabular}


(4) General corrosion resistance of the weld metal produced by E309 electrode is better than that produced by E2209 electrode.

(5) Because the weldments produced exhibit excellent mechanical properties and corrosion resistance, both of E2209 and E309 electrodes can be used to produce dissimilar metal weld by the SMAW process between 2205 DSS and X52 high strength low alloy steels.

Acknowledgments The authors gratefully acknowledge the Research Center in Industrial Technologies (CRTI) and express their sincere thanks to the Laboratory of Science and Materials Engineering (LSGM), for technical support provided in performing SEM-EDS, DRX and electrochemical studies.

\section{References}

[1] J. Lippold, D. Kotecki, Welding Metallurgy and Weldability of Stainless Steels (Wiley, New Jersey, 2005)

[2] A.R. Khalifeh, A. Dehghan, E. Hajjari, Acta Metall. Sin. (Engl. Lett.) 26, 721 (2013)

[3] J. Wang, M.X. Lu, L. Zhang, W. Chang, L.N. Xu, L.H. Hu, Int. J. Miner. Metall. Mater. 19, 518 (2012)
[4] M. Jafarzadegan, A. Abdollah-Zadeh, A.H. Feng, T. Saeid, J. Shen, H. Assadi, J. Mater. Sci. Technol. 29, 367 (2013)

[5] R. Kaçar, O. Baylan, Mater. Des. 25, 317 (2004)

[6] C. Pan, Z. Zhang, Mater. Charact. 33, 87 (1994)

[7] T. Vigraman, R. Narayanasamy, D. Ravindran, Mater. Des. 35, 156 (2012)

[8] P.B. Srinivasan, V. Muthupandi, W. Dietzel, V. Sivan, Mater. Des. 27, 182 (2006)

[9] R. Sridhar, K.D. Ramkumar, N. Arivazhagan, Acta Metall. Sin. (Engl. Lett.) 27, 1018 (2014)

[10] S. Wang, Q. Ma, Y. Li, Mater. Des. 32, 831 (2011)

[11] M. Sadeghian, M. Shamanian, A. Shafyei, Mater. Des. 60, 678 (2014)

[12] J.Y. Park, Y.S. Ahn, Acta Metall. Sin. (Engl. Lett.) 28, 32 (2015)

[13] R. Badji, M. Bouabdallah, B. Bacroix, C. Kahloun, B. Belkessa, H. Maza, Mater. Charact. 59, 447 (2008)

[14] C.J. Múnez, M.V. Utrilla, A. Ureña, E. Otero, Weld. Int. 24, 105 (2010)

[15] T.H. Chen, K.L. Weng, J.R. Yang, Mater. Sci. Eng. A 338, 259 (2002)

[16] A.V. Jebaraj, L. Ajaykumar, Procedia Eng. 64, 456 (2013)

[17] H. Sarlak, M. Atapour, M. Esmailzadeh, Mater. Des. 66, 209 (2015)

[18] G.R. Mirshekari, E. Tavakoli, M. Atapour, B. Sadeghian, Mater. Des. 55, 905 (2014) 